\title{
Decreasing of BOD Concentration on Artificial Domestic Wastewater Using Anaerob Biofilter Reactor Technology
}

\author{
Sri Sumiyati ${ }^{1, *}, P$. Purwanto ${ }^{2}$, and $S$. Sudarno $^{3}$ \\ ${ }^{1}$ Doctoral Program of Environmental Science, School of Postgraduate Studies, Diponegoro University, Semarang - Indonesia \\ ${ }^{2}$ Department of Chemical Engineering, Faculty of Engineering, Diponegoro University, Semarang - Indonesia \\ ${ }^{3}$ Department of Environmental Engineering, Faculty of Engineering, Diponegoro University, Semarang - Indonesia
}

\begin{abstract}
Pollution of domestic wastewater becomes an urban problem. Domestic wastewater contains a variety of pollutants. One of the pollutant parameters in domestic wastewater is BOD. Domestic wastewater which BOD concentrations exceeding the quality standard will be harmful to the environment, particularly the receiving water body. Therefore, before being discharged into the environment, domestic wastewater needs to be processed first. One of the processing that has high efficiency, low cost and easy operation is biofilter technology. The purpose of this research was to analyze the efficiency of BOD concentration reduction in domestic wastewater with anaerobic reactor biofilter using volcanic gravel media. The type of reactor used is an anaerobic biofilter made of glass which volume of 30 liters while the biofilter media is volcanic gravel. In this research the established HRT were 24, 12, 6 and 3 hours. The results showed that the efficiency of BOD concentration reduction in artificial domestic wastewater reached $80 \%$.
\end{abstract}

\section{Introduction}

Domestic wastewater contains numerous pollutants that are harmful to the environment. Pollutant parameters that exist in domestic wastewater, i.e.: BOD, COD, TSS, Ammoniac, fat, $\mathrm{pH}$ and temperature. If the pollutant concentration reaches over the quality standard and directly thrown away to the environment; then it will negatively affect to the human being and other living creatures. That is the reason why before throwing it to the environment, the domestic wastewater needs to be processed first. Today, the technology of domestic wastewater processing has been applied in the fields. One of the technologies, which have many advantages, is bio-filter/ bio-film technology. The advantages of biofilter technology, i.e.: cheaper, easy to use, and effective to decrease the pollutant parameter. As stated by [1], the bio-filter/ bio-film technology had very high efficiency on wastewater processing. [2] also stated that on applying the bio-film technology, it is rarely found the "bulking" matters so the processing becomes easy. According to [3], the used bio-filter media can be used for long term period without regeneration. Usage of biofilter media needs cleaning to remove the dirt on the surface. Besides, the bio-filter technology also does not produce much mud, so it does not need mud handling on its processing.

Some researchers used bio-film technologies had been done by some researchers, i.e.: [4] proceeded simulation wastewater using the decreasing of nitrogen and phosphor by bio-film algae. The result showed that the decreasing efficiency for each, Total Phosphor (TP)
98.17\%; Total Ammoniac (TN) 86.58\%; Ammonia Nitrogen (NH3-N) 91.88\% and COD 97.11\%. Besides, [5] did the domestic wastewater processing using biofilter of Moroccans sand, it was got the decreasing result as NH4-N and COD for $65 \%$ and $85 \%$.

That was the reason why the technology chosen for this research was a technology of anaerobic bio-filter. The choosing of bio-filter technology was due to cheap, easy to use and effective according to the high-efficiency value of the pollutant concentration decreasing. While the consideration to use anaerobic system was due to generally in any field, the application used was mostly anaerobic. Besides, the anaerobic system was not expensive on its operational. Different from aerobic system, it needed clower or aerator to add oxygen in the reactor, so it needed electricity that would increase the operational cost.

Media used in this research was volcanic gravel. Consideration to take volcanic gravel was due to it was available abundance in nature and the characteristic of volcanic gravel had the rough and uneven surface so it was effective as a place to stick the microorganism that would create the bio-film layer. The aim of the research was to analyze the concentration decreasing of BOD in the domestic wastewater by using anaerobic bio-filter technology. Pollutant parameter analyzed was BOD concentration on artificial domestic waste.

\section{Material and Methods}

Domestic wastewater that was processed on this research used artificial wastewater. Materials to create artificial

*Corresponding author: srisumiyati71@gmail.com 
domestic wastewater on this research were: skim milk powder (Source C), $\mathrm{KH}_{2} \mathrm{PO} 4$ (Source $\mathrm{P}$ ), $\mathrm{NH}_{4} \mathrm{Cl}$ (Source $\mathrm{N})$ and water [6]. All materials used to create artificial domestic wastewater were included pro analyst (p.a) material. Bio-filter media used, was volcanic gravel taken from one of the rivers in Yogyakarta, Indonesia. The size of volcanic gravel used in this research was about 2-5 cm, the shape of gravel was heterogenic, the chosen gravels were the ones which had the rough surface and not fragile. The used equipment on this research were: glass with thickness of $4 \mathrm{~mm}$, rectangle shaped with dimension of $40 \mathrm{~cm} \times 25 \mathrm{~cm} \times 30 \mathrm{~cm}$, submersible pump of AA 106 brand with the specification of voltage: $220-240 \mathrm{~V}$, frequency: 50/ 60 Hz, Watt: 85 W, F Max: 4000 L/H, Hmax: 4 meters. Other pieces of equipment used in this research were: peristaltic pump with the debit of $28 \mathrm{ml} /$ minute, plastic barrel with the volume of 200 liters, PVC pipe with the diameter of $1 / 2$ inch, covered bucket with the volume of 20 liters. Equipment to measure the BOD concentration in a laboratory were a spectrophotometer, BOD bottle, $\mathrm{pH}$ meter, thermometer, DO meter, volumetric flask, measuring cup, measuring pipette and BOD incubator. The sample taking was done in some sites. After sample taking in some sites, then the sample was tested for the BOD concentration in Environmental Laboratory, Department of Environmental Engineering, Faculty of Technique, Diponegoro University, Indonesia.

Design of anaerobic bio-filter reactor with the biofilter media of volcanic gravel was shown on Figure 1.

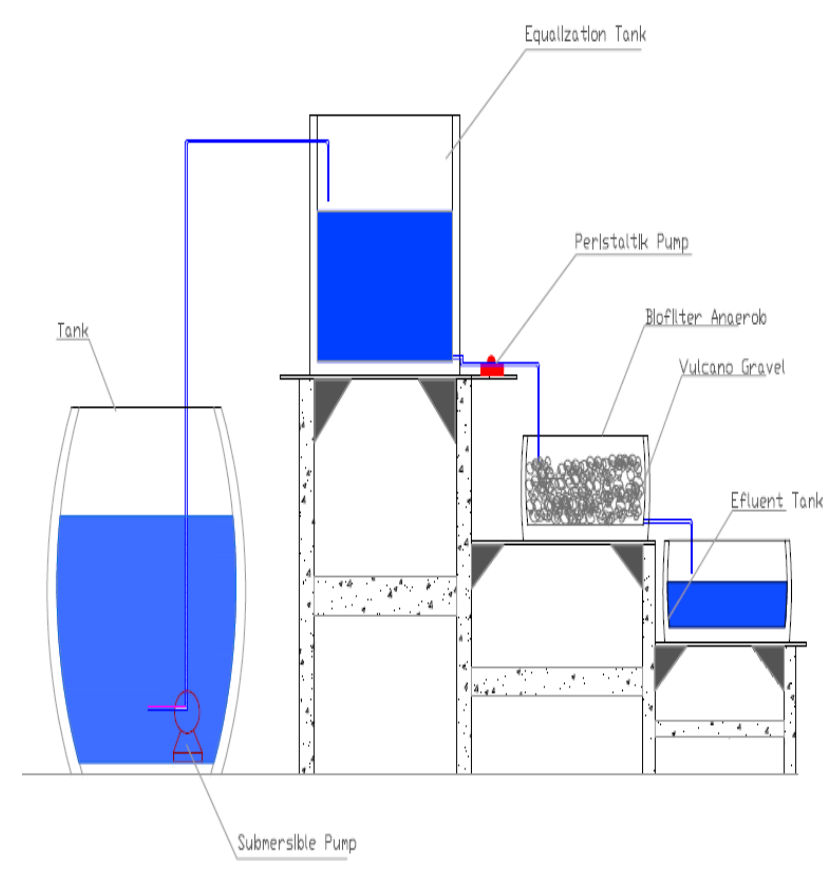

Fig. 1. Design of Anaerobic Bio-filter Reactor with Media of Volcanic Gravel.

\section{Results and Discussion}

\subsection{Research's Procedure}

This research was divided into three steps, i.e.: Seeding, acclimatization and running. The three steps were related each others. Seeding step was stepped to breeding microorganism. The purpose of this step was to grow the microorganism. Seeding on this step was done naturally. The waste was flown into the biofilm reactor with the anaerobic condition. A reactor that had been fulfilled by media and wastewater was then made the condition so that the micro-organism could grow on the median surface of the volcanic gravel. Furthermore, the acclimatization steps or called as a step of microorganism adaptation where in this step the microorganism had started growing and adapting inside the anaerobic reactor. The microorganism was breeding and sticking on the gravel media surface creating the bio-film layer.

This bio-film layer contained various micro-organism types, such as protozoa, bacteria, fungus, etc. As stated by [7], the bio-film layer contained some types of microorganism, such as bacteria, diatoms, fungus, algae, protozoa and non-cellular materials. According to [8], the bio-film layer was a micro-organism aggregate that adhered on the solid surface and the existence of Extracellular Polymeric Substance (EPS). The acclimatization step was ended up after the condition of bio-film layer reached steady state. Next, it was done the step of reactor operating (running). Running was done by flow the wastewater continuously with the debit set up according to the time to stay that had been set. The setup time-to-stay in this research were 24 hours, 12 hours, 6 hours and 3 hours.

\subsection{Analysis of BOD Concentration Decreasing Efficiency on Domestic Wastewater According to Residence Time}

On this research, the analyzed pollutant parameter was BOD concentration. The BOD concentration of domestic wastewater was set on the concentration of $492.35 \mathrm{mg} / \mathrm{l}$, $\mathrm{pH} 7.1-8.1$ while the temperature was set on $27.6-$ $28.3^{\circ} \mathrm{C}$. The chart of efficiency of BOD concentration decreasing on wastewater according to time to stay was shown on Figure 2.

On Figure 2, it was shown that the chart of efficiency of BOD concentration decreasing generally experienced assertion. In the 24 hours HRT time, the efficiency of BOD concentration decreasing started from the lowest of $10.81 \%$ until reached the highest efficiency on the 8 th day that was $66.39 \%$. While on HRT 12 hours, the efficiency had been increased on the first day $69.62 \%$ and reached the highest value on the second day, which was $72.85 \%$. On HRT 6 hours, the lowest efficiency was $34.68 \%$ and the highest was $73.82 \%$. On HRT 3 hours, the lowest efficiency was $57.34 \%$ while the highest was $88.36 \%$. 


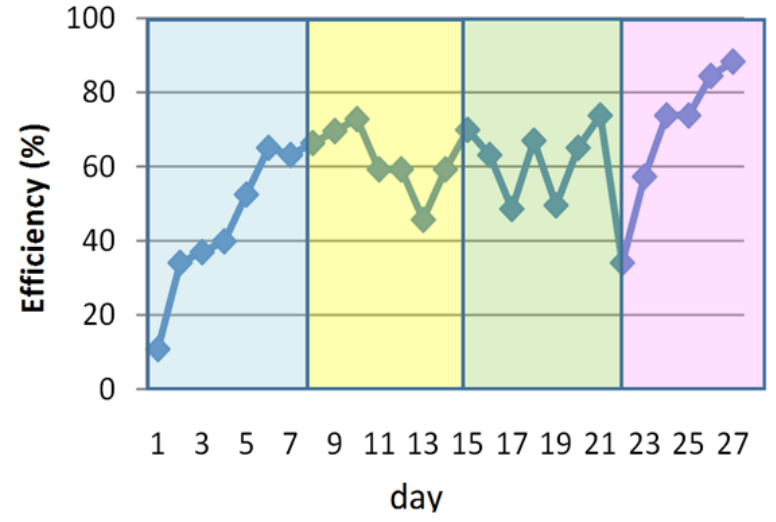

Fig.2. Chart of efficiency of BOD concentration decreasing on Anaerobic condition.

On the result of this research, it could be seen that on all HRT happened the degradation of organic compounds in the domestic wastewater that was marked by BOD concentration decreasing compared to the earlier concentration. From the Figure 2, it could be seen that for HRT 24 hours happened the increasing of efficiency on almost all time observations. Whereas on HRT 12 hours and 6 hours the charts trend tended to be stationary with the efficiency that was relatively stable. On HRT 3 hours, the efficiency also experienced the ascension in all time observations until reached the highest efficiency, which was $88.36 \%$.

\section{Conclusion}

The wastewater processing used anaerobic biofilter technology with volcanic gravel medium was effective to decrease the BOD concentration, which the highest efficiency of $88.36 \%$.

\section{References}

1. N. Houda, C. Abdelwaheb, B.R. Asma, M. Ines, L. Ahmed and H.Abdennaceur,CurrMicrobiol. 70:602609.(2015)

2. N.I. Said,JAI.1, 1 (2005)

3. D.S. Chaudhary, S. Vigneswaran, H.H. Ngo, H.S.D. Moon, Korean J. Chem. Eng. 20, 6, 1054-1065. (2003)

4. Q. Wei andG. Zhiguan, Front. Environ. Sci.Engin. 2, 4, p:446-451 (2008)

5. K.I. Yettefti, S. Etahiri, D. Malamis, O. Assobhei, Carpathian Journal of Earth and Environmental Sciences 8, 3 p: 207-218 (2013)

6. I. Nopen, C. Capalozza and P.A. Vanrolleghem, Technical Report. Department of Applied Mathematics, Biometrics and Process Control. Universiteit Gent. Belgium. July,p : 4 (2001)

7. S.G. Wesley, S. Satheesh, Journal of Experimental Marine Biology and Ecology, 379, p: 1-7. (2009)

8. Donian, Biofilms: Microbial Life on Surfaces. Emerging Infectious Diseases 8, p: 881 - 890 (2002) 